LICENÇA CC BY: Artigo distribuído sob os termos Creative Commons, permite uso e distribuição irrestrita em qualquer meio desde que o autor credite a fonte original.

\title{
CORPO-SIGNO: DIÁLOGOS ENTRE LABAN E BAKHTIN NO ENSINO SUPERIOR EM ARTES CÊNICAS ${ }^{1}$
}

\author{
SIGN-BODY: DIALOGS BETWEEN LABAN AND BAKHTIN ON HIGHER \\ EDUCATION IN THE PERFORMING ARTS \\ CUERPO-SIGNO: DIÁLOGOS ENTRE LABAN Y BAKHTIN EN LA \\ ENSEÑANZA SUPERIOR EN ARTES ESCÉNICAS
}

Jean Carlos Gonçalves ${ }^{1}$

Thais Castilho'

'Programa de Pós-Graduação em Educação, Universidade Federal do Paraná, Curitiba, PR, Brasil.

Artigo recebido em: 29/03/2020

Aprovado em: 03/11/2020

Resumo: O presente artigo é fruto de um estudo sobre as reverberações das práticas de Ballet Clássico no ensino superior em Artes Cênicas, que promoveu a triangulação entre as pesquisas em dança, o Pensamento Labaniano e a perspectiva dialógica de Bakhtin e o Círculo. Neste trabalho, o objetivo consiste em discutir a noção de corpo-signo. Como resultados, compreendeu-se o corpo como uma instância viva, que mergulha na cultura imaterial de sua sociedade para incorporar e enviesar esteticamente os signos nela pulsantes, por isso, é considerado um corpo-signo, o qual profere enunciados-dançados carregados de múltiplas vozes, impregnados de sentido, sendo capaz de transformar constantemente seu horizonte plásticovalorativo.

Palavras-chave: Corpo-Signo; Enunciado-Dançado; Ensino Superior em Artes Cênicas.

Abstract: This article is the result of a study on the repercussions of Classical Ballet practices in higher education in the Performing Arts, which prompted a triangulation of studies on dance, Labanian Thought, and the dialogical perspective of Bakhtin and the Circle. This work discusses the notion of "sign-body". It concludes by understanding the body as a living instance, which dives into the immaterial culture of its society to incorporate and aesthetically arrange the signs pulsating within it; thus, it is considered a sign-body, which utters enunciation-dancing loaded with multiple voices, impregnated with meaning and capable of expanding its plastic and evaluative horizon.

Keywords: Sign-Body; Enunciation-Dancing; Higher Education in the Performing Arts.

Resumen: Este artículo es el resultado de un estudio sobre las reverberaciones de 
las prácticas de ballet clásico en la educación superior en artes escénicas, que promueve la triangulación entre las investigaciones de la danza, el Pensamiento Labaniano y la perspectiva dialógica, por Bakhtin y el Círculo. En este trabajo, el objetivo es discutir la idea del «cuerposigno». Como resultado, entendemos el cuerpo como una instancia viva, que se submerge en la cultura no material de su sociedad para incorporar y organizar estéticamente los signos que palpitan en ella, por lo tanto, se considera un cuerpo-signo, que pronuncia enunciadosbailados cargados de múltiplas voces, impregnados de sentidos, que es capaz de ampliar su horizonte plástico y de valoración.

Palabras clave: Cuerpo-Signo; Enunciado-Bailado; Educación Superior en Artes Escénicas.

\section{Introdução}

O presente artigo é fruto de um estudo sobre as reverberações das práticas de Ballet Clássico no ensino superior em Artes Cênicas, que promoveu a triangulação entre as pesquisas em dança, o Pensamento Labaniano e a perspectiva dialógica, de Bakhtin e o Círculo². Neste trabalho, o objetivo consiste em discutir a ideia de corpo-signo e suas potencialidades na formação de artistas do corpo e da cena.

Os alunos de um curso de Bacharelado em Artes Cênicas, situado no interior do Paraná, tornaram-se os colaboradores da investigação, sendo eles sujeitos atravessados por diferentes práticas corporais, que atuam por meio das memórias da carne e dos enunciados de seus gestos, fenômenos imbuídos de autoria.

No primeiro semestre de 2019, foram realizadas, junto aos alunos colaboradores da pesquisa, oficinas de ballet, cuja técnica foi (des)construída pelo Pensamento Labaniano, passando pelo estudo das quatro Categorias já conhecidas por estudiosos de Laban: Corpo, Forma, Espaço e Expressividade. Ao final, os graduandos produziram Protocolos Verbo-Visuais de Dança ${ }^{3}$, a fim de sintetizar suas lembranças, sensações e entendimentos sobre o processo. Tais registros poéticos se tornaram o corpus da investigação e foram confrontados por meio da Análise Dialógica do Discurso, que tem em Bakhtin e o Círculo seu aporte teórico-metodológico.

O Pensamento Labaniano aqui se refere ao desdobramento da Coreologia de Rudolf Laban (1879-1958), que apresenta uma abordagem didática-filosófica para trabalhar com o movimento dançante. Recorremos a este termo para enfatizar um Laban pluralizado pelas vozes de seus colaboradores, um Laban contemporâneo e até mesmo "brasileiro", como diria Marques (2019); sobretudo, um Laban dialógico, pois a Coreologia ganha (ao mesmo tempo em que oferece) contribuições de Bakhtin e o Círculo.

Por estarem abertas a interlocuções, as obras de Laban foram atualizadas por grandes discípulos e colaboradores. O filósofo "desencadeou um processo em que foi até ofuscado pelo sucesso de seus alunos: Joss, Mary Wigman, Leeder, Bartenieff..., cumprindo assim seu objetivo, ou seja, colocar em movimento uma ideia, uma emoção, um sentimento" (MOMMENSON, 2006, p.17). 
Em 1965, Irmgard Bartenieff formulou a teoria correspondente ao Corpo, e Warren Lamb, entre 1950-60, estruturou o conceito de Forma, as quais foram somadas aos fundamentos de seu Mestre. A partir disso, a Coreologia Labaniana se desdobrou em Quatro Categorias: Corpo, Expressividade, Forma e Espaço, que dialogam e se complementam, trazendo ao mundo o Laban Movement Analysis (LMA), conhecido como Sistema Laban/Bartenieff (SCIALOM, 2017).

Todavia, Marques $(2011 ; 2010)$ alerta que não podemos nos esquecer do lugar de fala do teórico, cujo discurso, datado do início do século XX, ainda tem indícios de vozes universalizantes e imperativas, por mais que ele objetivasse extrapolar posturas centralizadoras, o que torna importante contextualizar suas obras. É necessário adentrar no núcleo da Coreologia e atualizála no mundo atual, de acordo com os objetivos, corpos e contextos do processo de ensinoaprendizagem-criação em Dança.

Na era contemporânea, cada pesquisador pode (senão deve) sugerir novas possibilidades de compreender as obras do filósofo, dando vida a "um Laban diferente, adaptado a cada contexto em que o seu pensamento, ainda hoje, parece capaz de inventar", desdobrandose em "novos campos de conhecimento", novas maneiras de ensinar-pensar-criar Dança (GREINER, 2006, p. 82).

Entendemos que o acervo de Laban está vivo. Posto que, muito similar ao que acontece com os trabalhos do Círculo, não se trata de uma doutrina ou método cristalizado, e sim de uma abordagem, um approach que fornece postulados para a leitura dos gestos em interação com os espaços interno e externo.

Inclusive, suas propostas, "quando entendidas como campos de significação da linguagem da dança, podem ter papel primordial na compreensão e na desconstrução das técnicas codificadas", como é o caso do Ballet, pois permite trabalhá-las, justamente, mediante conscientização e interpretação de seus textos e subtextos, de modo a "des-velar, des-construir, des-cobrir, re-configurar as instancias históricas, sociopolítico-culturais, os afetos e sentidos embutidos" nas poses e nos passos sistematizados (MARQUES, 2010, p. 90).

Então, por meio da articulação teórica entre o Pensamento Labaniano e a Perspectiva Dialógica no que dizem respeito ao conjunto temático que interessa às artes do corpo, este trabalho pretende discutir a ideia de corpo-signo, a partir da defesa de que, ao dançar, o sujeito enuncia a si mesmo, fala de sua trajetória e revela as múltiplas vozes que o constituem.

\section{O que pode o Corpo-Signo?}

No início do século XX, Laban foi pioneiro ao propor que o corpo do artista, antes visto como matéria passiva, um instrumento reprodutor de passos, fosse entendido como o grande articulador, pensador e criador de sua dança, abrindo espaços para que o movimento seja compreendido como um fenômeno autoral. 
Laban propôs um sistema aberto de troca desafiadora entre teoria e prática, Arte e ciência, tema e método, experiência e linguagem, técnica e criação, pesquisador e pesquisado. Nesta perspectiva, o (passivo) objeto de estudo torna-se um sujeito ativo: o corpo deixa de ser um objeto de especulação científica ou dominação social para tornar-se agente de sua própria história, recontada/redançada através da pesquisa coreográfica. (FERNANDES, 2009, p.139).

O pensador austríaco apresentou a dança como um texto proferido pelo corpo, carregado de signos, que deve ser lido e interpretado. Ele apostava que, ao conhecer essa "ordem oculta da dança", os campos de significação plurais que constroem os passos, os artistas se abririam para novos posicionamentos, novas formas de comunicação e multiplicação de sentidos (MARQUES, 2010).

Nesta perspectiva, e com o intuito de aprofundar o entendimento do corpo como agente articulador, comunicador e produtor de sentidos, percebemos a importância de retomar a noção de signo ideológico, amplamente discutida pelos intelectuais bakhtinianos.

Para o Círculo, o signo se refere ao universo dos produtos do "espírito humano", elementos socialmente constituídos sobre/pela ética, arte, filosofia ou política, os quais configuram uma cultura imaterial, presente em imagens, objetos ou palavras, e são revestidos de sentidos a partir da interação entre os sujeitos (BRAIT, 2005).

A teoria dialógica compreende o ser humano como um sujeito que tanto constitui signos e seus sentidos, como também é constituído por eles, reciprocamente. É no diálogo com o outro, mergulhado em situações de interação, que o homem impregna de sentidos os objetos, as palavras, as obras artísticas, seu cotidiano, na medida que dá forma a sua própria consciência.

Com isso, o dialogismo, vinculado, indissoluvelmente, à alteridade, torna-se a base da produção dos discursos, dos atos humanos em geral, visto que o sujeito leva o outro em consideração, como parceiro ativo no processo de comunicação.

A vida é dialógica por natureza. Viver significa participar do diálogo: interrogar, ouvir, responder, concordar, etc. Nesse diálogo o homem participa inteiro e com toda a vida: com os olhos, os lábios, as mãos, a alma, o espírito, todo o corpo, os atos [...]. [Seu discurso] entra no tecido dialógico da vida humana, no simpósio universal. (BAKHTIN, 2011, p. 348).

O Círculo entende a alteridade como uma relação constitutiva entre os sujeitos, no entrelaçamento de enunciados durante os fenômenos discursivos. A interação entre o eu e o outro possibilita o desdobramento de vozes, que se interpenetram num espaço-tempo social e histórico. O outro se trata de uma referência, é a condição de existência do eu, tornando-se impossível pensar o homem apartado das relações que o constituem (AMORIM, 2009).

Diante disso, os discursos do sujeito não partem de si mesmo, ou se quer vieram ao mundo no exato momento da comunicação, como algo totalmente novo e estritamente particular. Seus enunciados, em diversas formas de expressão, na realidade se tratam de um conjunto de vozes, de uma pluralidade de dizeres que ecoam da/na sociedade.

Para os pensadores bakhtinianos, a consciência é multivocal, pois, a todo momento ela absorve os discursos, pensamentos e costumes do outro. As vozes ao redor formam um emaranhado de valores e experiências sociais, os quais acionamos durante nossas interações, 
mesmo que não consigamos reconhecê-las (GONÇALVES, 2010).

Não existe apenas um Eu, e sim um Nós. Conforme atua no meio, pelas mais variadas formas de comunicação, o sujeito se conecta à cultura imaterial socialmente constituída, dando novos valores ao horizonte axiológico de sua consciência. Durante a interação, o sujeito revela as vozes que ecoam em seus enunciados, fornece pistas sobre seu lugar de fala, as esferas e ideologias que o circundam. Em alguns momentos, tais vozes estão latentes, em outros mascaradas, mas todo discurso emerge de um jogo de vozes, como uma resposta ao(s) enunciado(s) do(s) outro(s).

A respeito do corpo, é possível entender que o gesto também se trata do enunciado de um sujeito, pois a perspectiva bakhtiniana compreende que todos os atos possuem valor semiótico-ideológico, qualquer material pode se tornar expressivo a partir da força psíquica do sujeito, desde a respiração e a circulação do sangue, até os movimentos do corpo (VOLOCHINOV, 2017).

Assim, nas Artes do Corpo, e aqui, em especial as do Corpo em Cena, os gestos, as palavras verbalizadas, os olhares lançados pelos artistas são considerados signos que se materializaram nos corpos, estão encarnados, vivos e em constante trocas com o outro.

Então, se o movimento é o enunciado do corpo, ao levar em consideração as questões de dialogismo e alteridade, é possível entender que o ato de se mover é constituído a partir de relações dialógicas com o corpo do outro. O movimento vem ao mundo em meio à contínua "cadeia de gestos" já existentes, ecos de ações corporais que vibram na sociedade. Para dançar, o corpo se apropria dos rastros de movimentos de seu espaço-tempo, das trocas com o ambiente, por meio de signos que fazem parte do jogo de vozes dançantes que o perpassam.

Com isso, a dança adquire o status de texto por ser um tecido organizado de informações, com um acabamento estético provisório, no qual ossos, pele e músculos se apropriam dos signos que os perpassam. Para o Círculo, o texto se configura como enunciado concreto, que pode ocorrer em diversas formas de expressão, como sons, imagens, cores ou ações corporais (VOLÓCHINOV, 2017).

Numa visão similar, Laban problematizava a noção biologizante e psicologizada de seu período, na qual o corpo era um instrumento controlado pela mente. Diferente dos artistas clássicos, o filósofo não estava interessado apenas nas formas corporais e nos passos virtuosos ditados por outrem, ou nos "produtos finais". Ele apostava na consciência e na experimentação do movimento pessoal, trazendo à tona as leis ocultas da dança: os elementos escondidos nos movimentos, que os fazem expressivos e funcionais, carregados de sentidos (MARQUES, 2010).

Para o teórico,

A dança como forma de expressão e comunicação, estimula as capacidades humanas e pode ser incorporada à linguagem oral, por exemplo. Assim como as palavras são formadas por letras, os movimentos são formados por elementos, a expressão estimula e desenvolve as atividades psíquicas de acordo com os seus conteúdos e na forma de ser vivida, tanto quanto a palavra. (LABAN 1990, p. 33). 
Laban lutava pela (re)conquista do discurso corporal, defendendo os gestos como a "parte visível do pensamento", o lugar onde se "aglutinam os elementos do discurso e criam [se] formas dinâmicas em que a estabilidade e mobilidade se alter(n)am continuamente" (FERNANDES, 2006, p. 23).

Como é possível perceber, Laban e o Círculo compartilham da ideia de um corpo social, sujeitado e inacabado, em constante transformação com/pelo meio, cujo movimento é o seu discurso.

É impossível provar que Bakhtin estava ciente dessas correntes culturais, mas certamente há uma conexão entre sua noção de corpo e performance celebrativa e as noções de Appia, Laban e outros - uma conexão que merece uma pesquisa futura. (MCCAW, 2015, p. 53). ${ }^{4}$

As duas teorias são contemporâneas entre si e pregam, a sua maneira, sobre um mundo constituído por signos, que invadem a materialidade carnal do ser humano e são (re) organizados na composição de obras artísticas.

Para o Pensamento Labaniano que vibra na contemporaneidade, análogo aos postulados do Círculo, é no/pelo corpo que emergem as obras de dança, e o signo permeia a ação humana, "como uma segunda pele por sobre a realidade", tratando-se de um organismo social que constrói complexos sistemas simbólicos e seus significados, os quais contêm a história e a dinâmica das relações de um grupo. Por meio dos signos e dos seus sentidos, "o movimento meramente funcional adquire uma pertinência valorativa", no ritmo/espaço social, que é transmitida "em vários planos simultâneos de percepção e compreensão". (MOMMENSOHN, 2006, p. 110-111).

Nessa esteira de pensamentos, entendemos que as duas teorias possibilitam a ideia de um corpo-signo, cujos movimentos, tanto habituais como artísticos, procuram sua matériaprima no mundo das relações:

Assim, na Arte, o significado é absolutamente inseparável de todos os detalhes do corpo material que a encarna. A obra de Arte é significativa em sua totalidade. A própria criação de um corpo-signo [tiélo-znak] tem aqui uma importância primordial. (MEDVIÉDEV, 2012, p. 54).

É preciso entender que na carne deste corpo-signo vibram as vozes de seu espaçotempo, e pelo diálogo alteritário o sujeito constitui seus estilos de "andar, parar, olhar, sorrir, gesticular, pular, sentar e levantar, ou seja, formas de ser-estar-agir no mundo" (GONÇALVES; CASTILHO; GABARDO JR., 2019, p. 150).

O movimento, portanto, é o enunciado do corpo-signo, e sua ação dançante tem o acabamento de texto artístico, uma obra proferida por um sujeito social e historicamente constituído. É aí que se torna possível pensar a Labanálise uma forma de ler este corpo-signo, já que um mapeamento baseado nas quatro Categorias (Corpo, Expressividade, Forma e Espaço) "pode ser comparado ao DNA, com suas quatro bases - Adenina, Guanina, Timina, Citosina - responsáveis pelo código genético". Da mesma maneira, organizadas em forma de espiral, interconectadas, uma Categoria interage com a outra, "provocando alterações e expansão das habilidades expressivas rumo ao Domínio do Movimento" (FERNANDES, 2001, p. 10-11). 
Por isso, apostamos na noção de enunciado-dançado, entendendo que o corpo não fala, pensa ou se move em momentos distintos, mas numa ação conjunta. O corpo não necessariamente quer dançar com o objetivo de contar uma história, traduzir palavras verbalizadas ou textos escritos em seus gestos. Para além dessa possibilidade, ele já enuncia a si mesmo, comunica o que que vê, sente e lembra, traz em sua materialidade os signos de sua trajetória (GONÇALVES; CASTILHO, 2016).

Posto isto, no âmbito da formação do artista cênico, reconhecemos a importância de que os acadêmicos compreendam o físico como um corpo-signo e o gesto como seu enunciadodançado, sendo o Pensamento Labaniano um dispositivo para analisá-los, cujos elementos coreológicos são importantes tanto para o sujeito ter referências e autonomia ao realizar suas próprias composições, quanto para poder observar conscientemente as obras que veiculam em seu meio.

Não obstante, torna-se delicado se referir ao movimento como um gesto estritamente pessoal, único e inédito. Pois, a partir da teoria bakhtiniana, verificamos que o ser humano não é a origem de seu dizer, seus movimentos carregam vozes, ecos de seu espaço-tempo, com sentidos oriundos das situações de interação. Ou seja, o enunciado-dançado de alguém é proferido em conexão com o meio, mergulhado nas redes de relações, conectado às danças que vibram na cadeia discursiva-artística. Como a vida é dialógica por natureza, o corpo-signo não inventa um movimento de súbito e exclusivo.

\section{Enunciado-Dançado: o corpo-signo em autoria}

O Pensamento Labaniano apresenta uma visão holística de dança, na qual corpo, mente e espírito formam uma unidade, e o movimento expressivo é o resultado do diálogo interdependente entre essas instâncias. Com isso, "não é possível separar conceitos abstratos, ideias e /ou pensamentos da experiência corporal"; o corpo (também) corresponde à dimensão pela qual "podemos dizer, pensar, saber e comunicar", sendo a unidade corpo-mente-espírito a base das obras labanianas (RENGEL, 2006, p. 122). Não se pode atribuir apenas à mente a função intelectual e criativa, como se o físico fosse apenas um envoltório orgânico, sem vida, que aguarda para ser comandado pelas ordens psíquicas. A "pesquisa de Laban procurou encontrar sentido no corpo vivo", posto que o pensar e o sentir acontecem ao mesmo tempo, estando "o corpo e o cérebro agindo num continuum" (GREINER, 2006, p. 80-81).

De acordo com McCaw (2011), no pensamento de Laban, para cada movimento ocorrem inúmeras tensões individuais e profundas no corpo, condicionadas pela estrutura e organização anatômica. É importante lembrar que a forma externalizada do movimento, sua imagem espacial, não é composta apenas pela representação de um evento interno, nem mesmo pela reprodução secundária e posterior aos processos cognitivos. Esta forma externalizada poderia ser concebida como o reflexo exato das imagens, dos pensamentos e das conclusões da interioridade do sujeito. 
Assim, os sentimentos, as lembranças, a organização de ideias não são processos exclusivamente mentais e encarcerados no cérebro, mas acontecem por todas as células, nas entranhas da materialidade carnal, na medida que o corpo, em sua concretude, promove sua dança. Ainda segundo McCaw (2011), conforme o corpo físico se aprimora e se torna uma unidade ativa, com as estruturas orgânicas em plena conexão, refina-se o diálogo interdependente entre a mente e o espírito, de maneira que o sujeito possa integralizar-se como ser.

O corpo discursa, profere enunciados-dançados, o que releva não somente no contexto da formação superior em Artes Cênicas, caso desta pesquisa, mas também em outras esferas de educação, a importância de metodologias que deem vida ao físico, que despertem sua lucidez anatômica, a inteligência dos músculos e a memória dos ossos. Estima-se que, ao conhecerem suas possibilidades, ordenações e conexões, é que os sujeitos passam a permitir que seus corpos atuem vivos e integrados. Pois "corpos que se conhecem têm grandes possibilidades de estabelecer diálogos diferenciados com os outros, com o meio e com o mundo" (MARQUES, 2010, p. 206). Partindo desta discussão, importa ressaltar o quanto é necessário que as Artes do Corpo encontrem, no campo da pesquisa das práticas em educação, o seu lugar e visibilidade.

De fato, quando o sujeito encara seu físico como um instrumento, as relações que estabelece são de submissão, "e talvez este corpo não esteja tão vivo assim". Sob essa conduta, o corpo não está apenas objetivado, como também desterritorializado, sendo necessário "enraizá-lo", torná-lo flexível e (multi)relacional, exercitar sua autonomia (FERNANDES, 2006, p. 372). Numa visão convergente, a perspectiva bakhtiniana também se refere ao físico como uma instância constitutiva do ser, afirmando que suas dimensões interior e exterior estão imbricadas:

O corpo interior - meu corpo enquanto elemento de minha autoconsciência - é um conjunto de sensações orgânicas interiores, de necessidades e desejos unidos em torno de um centro interior; já o elemento externo, como veremos, é fragmentário e não atinge autonomia e plenitude, tem sempre um equivalente interior que o leva a pertencer a unidade interior. Não posso agir de forma imediata ao meu corpo exterior: todos os tons volitivos-emocionais diretos, que em mim estão ligados ao corpo, dizem respeito ao seu estado interior e às suas possibilidades como sofrimento, gozos, paixões, satisfações, etc. (BAKHTIN, 2011, p. 44).

Além disso, para Bakhtin, a Dança é um evento rico em diálogos, constituindo-se em uma arena de vozes que desperta conhecimentos sobre si e sobre o outro, na qual o sujeito pode preencher de sentidos seu corpo e seus atos a partir do encontro com o outro - processo que vai chamar de sofianidade, ligado ao termo grego sofia, correspondente a promover sabedoria:

$\mathrm{Na}$ dança, minha imagem externa, que só os outros vêem e só existe para eles, funde-se com o meu ativismo interior orgânico que sente a si mesmo; na dança, tudo o que em mim é interior, procura exteriorizar-se, coincidir com a imagem externa; na Dança eu me condenso mais na existência, familiarizo-me com a existência dos outros; em mim Dança a minha presença (ratificada axiologicamente de fora), a minha sofianidade, o outro Dança em mim. (BAKHTIN, 2011, p 125).

A arte do movimento está carregada de vozes. Por meio de enunciados-dançados, engajados no diálogo com o outro, o corpo-signo pode produzir, ressignificar e transformar sentidos. Porém, entendemos que não é qualquer prática que dará a oportunidade ao sujeito de mergulhar na cadeia discursiva com seu corpo, atingindo o potencial transcendente da 
Dança, alcançando sua sofianidade, pois "as propostas metodológicas, os caminhos e as trajetórias de ensino - o 'como' se ensina e se aprende - são determinantes nos processos de educação e transformação" (MARQUES, 2010, p.138).

A noção de transformação supracitada se refere aos processos (cri)ativos e sensibilizadores que as práticas dançantes podem (e devem) fornecer, ao permitir que o artista se conecte com as redes de relações entre a Dança, a Arte e o mundo, o que "possibilita o trânsito entre conhecimentos, múltiplos diálogos, fluxos de reordenação de tempos e espaços sociais vividos, percebidos e imaginados nos/pelos corpos que dançam" (MARQUES, 2010, p. 222). Esse fenômeno dialógico é inerente à própria Arte, permite aos artistas ressignificarem suas ações no mundo, seus modos de ser-estar, suas escolhas artísticas, sua própria existência.

Diante disso, na esfera da graduação em Artes Cênicas, identificamos a importância de vivências artístico-pedagógicas que levem os acadêmicos a perceberem a "ordem oculta" de seus movimentos, a partir do Pensamento Labaniano, a fim de analisarem os signos e as significações que seus corpos enunciam. Desse modo, além de se conscientizarem de tais elementos expressivos, podem também brincar com eles, reorganizá-los, administrá-los criativamente em diferentes enunciados-dançados.

Levando em consideração o diálogo entre o Pensamento Labaniano e a Perspectiva Dialógica, apostamos em processos de ensino-aprendizagem-criação transformadores, que instiguem os discentes a agirem na condição de autores, permitindo que seus corpos-signos ganhem novos horizontes plásticos e valorativos.

A respeito da autoria, o Círculo designa por autor tanto o autor de enunciados cotidianos, como o de obras artísticas, numa noção de autoria amplificada. Sua concepção semióticofilosófica sobre a relação entre a cultura e os sujeitos aponta que os artistas criam suas obras bebendo no rio de seus signos, submersos no diálogo com o outro.

Ao reconhecer a dança como um enunciado-dançado, um ato enunciativo-discursivo, compreende-se também que "sua própria natureza comunicativa implica autoria, irrepetibilidade e singularidade" (GONÇALVES; CASTILHO, 2016, p. 25). Todo enunciado é prenhe de resposta, ou seja, atos implicados em autoria. "Não há linguagem sem possibilidade de diálogo, isto é, sem possibilidade de resposta. Falar é falar a outros que falam e que, portanto, respondem" (AMORIM, 2004, p. 95).

Os seres humanos constituem sua relação simbólica com o mundo dado, transformando-o num mundo postulado. Isto é, o mundo dado, no qual o sujeito é lançado, é transfigurado por ele, a partir do diálogo, de suas (cri)ações, do jogo que acontece nas arenas de vozes. Criar, para a perspectiva bakhtiniana, não se restringe às composições artísticas, mas a uma postura inerente ao sujeito - ativo, responsivo, produtor de sentidos.

O autor-artista, por sua vez, é "[...] o agente da unidade tensamente ativa do todo acabado, do todo da personagem, do todo da obra, e este é transgrediente a cada elemento particular desta" (BAKHTIN, 2011, p. 10). O sujeito coloca-se, assim, em tensa relação dialógica para com sua obra, interagindo com seus elementos e escolhendo os caminhos do processo 
criativo, como uma consciência criadora, uma figura de mediação semiótica, que brinca com os signos, os símbolos e as significações.

Por ter um excedente de visão, como se tivesse uma memória expandida de passado, presente e futuro, o autor-artista possui o domínio dessa obra. No processo de criação, implicado em alteridade, o texto é permeado por vozes, pelos rastros de outras obras, ecos que atribuem sentidos a sua criação.

O autor-artista é "quem dá forma ao conteúdo: ele não apenas registra passivamente os eventos da vida [...] mas a partir de uma certa posição axiológica, recorta-os e reorganizaos esteticamente" (FARACO, 2005, p. 38). Ele escolhe, redireciona, sente e reflete os elementos do mundo a sua maneira, sempre por um viés valorativo, criativo, sensível à multiplicidade e à heterogeneidade das vozes sociais.

A perspectiva bakhtiniana não nega a autoria individual, não recusa a singularidade, pelo contrário, afirma que cada ser humano ocupa um lugar único e insubstituível. Porém, alerta que nada rompe o silêncio do mundo, nenhum discurso se manifesta de repente, todo enunciado vem à tona a partir da cadeia de enunciados já existentes, toda obra artística se constitui na esteira de obras artísticas que vibram no grande tempo - sejam as produções realizadas em espaço-tempos longínquos, ou nos mais próximos, frutos das esferas em que o artista está inserido.

Com maior ou menor grau de seu ativismo, o autor "dá forma ao conteúdo: ele não apenas registra passivamente os eventos da vida", mas os recorta e reorganiza esteticamente (FARACO, 2009, p. 89-90). No entanto, o estado de consciência ou alienação, o nível de domínio dessa ação, a postura de encarar o corpo como um organismo a ser moldado ou uma instância viva e (cri)ativa, é o que diferencia o grau de responsividade, o grau de autoria do aluno-artista - o qual deve ser fomentado pelas propostas artístico-pedagógicas do docente durante o processo formação acadêmica.

A esfera da educação superior é um lugar onde a Arte e a Educação se enfrentam e se justapõem, pois nela existe a busca pela experimentação e pela criação artística, haja vista exemplos históricos de resistência, de forças centrífugas descentralizadoras, ao passo que "carrega consigo marcas da academia: suas organizações, suas burocracias, suas avaliações; aspectos que estão relacionados ao ambiente educacional" (GONÇALVES, 2019, p. 52).

A graduação em Artes Cênicas se revela como o lugar da pesquisa de gestos, de estudos teórico-práticos, de experiências compartilhadas que suscitam posicionamentos ativos entre docentes e alunos. O professor não é visto mais como um mestre a ditar roteiros de movimentos ao grupo, de acordo com seus próprios anseios - não é o detentor absoluto do conhecimento, mas um orientador, mediador e estimulador das qualidades singulares dos discentes. Estima-se que o graduando traga "no seu corpo, no seu movimento e no seu repertório de informações os rastros da sua trajetória de vida, tornando-se o principal protagonista no binômio ensinoaprendizagem" (SILVA, 2016, p.34). 
Para as lentes bakhtinianas, como "o sujeito é constituído nas suas relações, por meio da interação que acontece no jogo de vozes enunciativas, o aluno é constituído pelo professor e vice-versa" (GONÇALVES, 2011, p. 49). Todas as escolhas carregam sentidos; atos artísticos e pedagógicos são impregnados e impregnadores de valores, que serão determinantes na formação dos acadêmicos, enquanto artistas e atores sociais.

Posto isto, enfatizamos que discentes e docentes se constituem e se transformam mutuamente, promovendo uma arena de vozes dançantes, um jogo por onde se estima que os corpos-signos ampliem seu horizonte plástico-valorativo. Assim, ao dançar de modo consciente, responsivo e (cri)ativo, os alunos protagonizam essa grande festa de renovação de sentidos, o que os possibilita a condição de autores, em meio à gama discursiva da qual fazem parte ao dançar.

\section{In-Conclusões: o que pode o corpo-signo no ensino superior em Artes Cênicas?}

O corpo é uma instância viva, que mergulha na cultura imaterial de sua sociedade e incorpora, recorta e enviesa esteticamente os signos nela pulsantes. Por isso, é considerado um corpo-signo, aquele que profere enunciados-dançados carregado de vozes, impregnadas de sentidos.

Todavia, é importante destacar que, em abordagens tradicionalistas de dança, o sujeito realiza gestos encarando seu corpo como uma máquina a ser manipulada por seu cérebro ou pelo professor, sem estabelecerem entre si relações profundas e saudáveis. Nestas abordagens, o aluno não toma consciência de suas possibilidades anatômico-fisiológicas, além de não prezar pela análise dos textos e subtextos da dança, agindo de forma submissa e alienante.

Nessa pedagogia, as relações entre o artista e o professor, entre o eu e o outro, são estritamente enformadoras, em vez de informadoras, muito menos transformadoras negando a própria sublimidade da arte. O olhar do outro não é amoroso, não traz simpatia ou compaixão, como diria Bakhtin, pois o docente não visa manter um diálogo empático e afetuoso, mas uma voz autoritária e imperativa, por vezes mascarada.

Há algum tempo, livros e artigos acadêmicos vêm reforçando a importância de ressignificar as técnicas de dança, promovendo vivências de investigação e conscientização do movimento, no intuito de despertar o domínio do corpo, dos gestos e da criação artística nos aprendizes. Entretanto, ainda há muito o que pesquisar e compreender a respeito de metodologias (cri)ativas, que instiguem o potencial autoral do que aqui denominamos corpossigno, especialmente no contexto do ensino superior.

Pelas lentes bakhtinianas, entendemos que a esfera universitária possui um jogo de vozes com forças centrípetas e centrífugas, o que a consolida como um campo de atividade humana repleto de discursividade. Na teoria dialógica, os enunciados dos sujeitos, sejam eles 
verbais, imagéticos, gestuais ou escritos, sempre estão inseridos num ambiente de (inter) relação social, dentro de contextos que delimitam os gêneros discursivos - as temáticas, as formas e os estilos dos discursos que ali são proferidos (GONÇALVES, 2019).

Os modos (relativamente) estáveis de enunciação, a maneira como os sujeitos escolhem para dialogar, vão criando corpo, valorações e dão o acabamento provisório das formas de comunicação de uma determinada esfera - um campo de relação humana, como a religião, a família, a escola, a universidade (GRILLO, 2008).

Os cursos superiores em Artes Cênicas, portanto, vão constituindo sua cultura a partir das interações entre os sujeitos, com ritos, rotinas, costumes, formas de lecionar e avaliar, de produzir pesquisas, projetos e obras artísticas. Atualmente, as práticas desenvolvidas nessa esfera confrontam-se com a hierarquização de técnicas e métodos e com pensamentos universalizantes, afastando-se da reprodução acrítica de movimentos em prol da liberdade de criação dos alunos.

Por se tratar de um contexto educacional, nutrido pelo processo de escolarização, a herança tradicional está presente no modelo disciplinar de currículo, nos formatos de avaliação, nas relações entre professor-aluno, aluno-aluno e professor-professor, além da maneira com que as artes do corpo se articulam com o pensamento científico.

Marques $(2010 ; 2011)$ lembra o quanto, por ironia, a universidade pode lançar vozes opressoras e hierarquizantes, reproduzindo os valores iluministas que tanto almeja combater:

O ensino universitário, que poderia funcionar como foco de expansão de conhecimento e pesquisa na área de ensino da dança, acaba em muitos casos, juntamente com o ensino básico, por perpetuar o autoritarismo da didática tradicional: autoritarismo nos discursos, do professor, dos planejamentos, dos objetivos, dos sistemas de avaliação. (MARQUES, 2011, p. 54).

Um dos exemplos que ela cita é a predileção em trabalhar com as teorias de Laban apenas como vivências de Educação Somática, com aulas introspectivas, quase terapêuticas, sem ter um planejamento para o avanço desse (auto)conhecimento, para a abertura do corpo para as relações entre a arte, o ensino e a sociedade.

Corroborando com a autora, percebemos que tal tendência criou um status de ação pedagógica intelectualizada, por vezes com ares de superioridade, mas "conectar-se ao corpo mediado pelas vivências de Educação Somática ou de outras propostas de sensibilização e autoconhecimento não garante, por si só, conexões com a produção artística", com isso, não fomentam a capacidade de criação do sujeito (MARQUES, 2010, p. 206).

Concordamos com a artista sobre esse isolamento ser ingênuo e contraditório à própria dança, a qual implica diálogo com o outro, fruto dos encontros que possuem textos e subtextos enunciados pelo corpo, ou seja, campos de significação que devem ser compartilhados com as redes de relações existentes no mundo.

Ademais, para o Círculo "é o corpo exterior apreendido visualmente que produz significado", o que problematiza o feedback interno do corpo, sua análise sobre si mesmo, contestando a capacidade do sujeito de se compreender em sua totalidade apenas pelos 
sentidos proprioceptivos e cinestésicos (MCCAW, 2019, p. 44). As formas plásticas que o corpo constrói não pertencem somente ao sujeito, pois este não consegue alcançar a consciência de si, necessitando sempre do outro para lhe fornecer acabamento.

O artista não tem condições de perceber a totalidade de sua arquitetônica corporal ao mesmo tempo em que está englobado por ela. Não consegue se olhar de fora, e suas reações volitivo-emocionais não permitem uma conclusão sobre si, assim, seu acabamento, mesmo que provisório, só pode ser contemplado pelo outro. As esculturas criadas por um corpo dançante, suas manifestações imagéticas, carregadas de signos, são revestidas de sentidos no encontro, na fronteira, na valoração entre a autoconsciência e o olhar outro.

O corpo exterior está unificado e enformado por categorias cognitivas, éticas e estéticas, por um conjunto de elementos visuais externos e táteis que nele são valores plásticos e picturiais. Minhas relações volitivo-emocionais ao corpo exterior do outro são imediatas, e só em relação ao outro eu vivencio imediatamente a beleza do corpo humano, ou seja, esse corpo [do outro] começa a viver para mim num plano axiológico e inteiramente diverso e inacessível à autossensação interior e à visão fragmentária [desse sujeito]. (BAKHTIN, 2011, p. 47 - ênfase minha).

Diante disso, na graduação em Artes Cênicas, acreditamos que nem mesmo os improvisos, jogos ou treinamentos corporais sistematizados devem ser sinônimo de "mover-se por moverse", de meras reproduções de tendências, de ações mecânicas ou puramente introspectivas, sem objetivos artístico-pedagógicos transcendentes. Devem, no entanto, "constituir-se em ações problematizadas por um fazer-pensar, tornando-se uma vivência sensibilizadora e produtora de sentidos, alcançando, desse modo, a dimensão da Arte - o lugar da ressignificação, da transcendência, por fim, da transformação" (GONÇALVES; CASTILHO; GABARDO, 2019, p. 145.)

Desse modo, a questão que ascende dessa pesquisa se refere a como os artistas decidem agir diante do jogo de vozes centrípetas e centrífugas que se justapõem dentro da universidade. Tanto o discente quanto o docente estão submersos na arena de vozes dançantes do processo de ensino-aprendizagem-criação, que podem estar mais vinculadas a uma prática passiva, que perpetua tendências tradicionais (ou tradicionalizadas) no meio acadêmico, ou a um modus operandi capaz de potencializar a capacidade de resposta, crítica e transformação. Este último oferta, a no nosso ver, a ampliação do horizonte plástico-valorativo de todos os participantes da situação de comunicação discursiva, que, no caso desse estudo, é o ambiente de ensinoaprendizagem da dança no contexto de formação superior em Artes Cênicas.

\section{Referências}

AMORIM, M. Para uma filosofia do ato: "válido e inserido no contexto". In: BRAIT, B. (Org.) Bakhtin, dialogismo e polifonia. São Paulo: Contexto, 2009.

O pesquisador e seu outro: Bakhtin nas ciências humanas. São Paulo: Musa, 2004.

BAKHTIN, M. Estética da criação verbal. São Paulo: Editora WMF Martins Fontes, 2011.

BRAIT, B. Bakhtin e a natureza constitutivamente dialógica da linguagem. In: BRAIT, B. (Org.). Bakhtin, dialogismo e construção de sentido. Campinas, SP: Ed. da UNICAMP, 2005, 
p.87-98.

CASTILHO, T. A arena de vozes dançantes na escola: aproach bakhtiniano sobre a formação do artista-docente. Anais da XII ANPEd-SUL, 2018. < http://anais.anped.org.br/regionais/p/ sul2018/trabalhos> Acesso em 27/03/2020.

Vozes da Dança na Escola: o Ballet Clássico em perspectiva verbo-visual. Dissertação de Mestrado. Curitiba: Universidade Federal do Paraná, 2016.

FARACO, C. A. Autor e autoria. In: BRAIT, B. Bakhtin: conceitos-chave. São Paulo: Contexto, 2005.

Linguagem \& diálogo: as ideias linguísticas do Círculo de Bakhtin. São Paulo: Parábola Editorial, 2009.

FERNANDES, C. Esculturas líquidas: a pré-expressividade e a forma fluida na dança educativa (pós) moderna. Campinas: Caderno CEDES, vol.21, no.53, 2001.

O corpo em movimento: o sistema Laban/Bartenieff na formação e pesquisa em artes cênicas. 2. ed. São Paulo: Annablume, 2006.

O perfil de movimento de Kestenberg: categorias de análise e aplicação preliminar em dança. Revista Poiésis, n. 13, p. 135-144, 2009. DOI: https://doi.org/10.22409/ poiesis. $1013.135-144$

GONÇALVES, J. C. A prática de montagem como prática pedagógica. Florianópolis: UDESC. Urdimento- Revista de Estudos em Artes Cênicas, Junho 2010, n. 14. DOI: https://doi.org/1 0.5965/1414573103362019145.

Teatro e Universidade: Cena. Pedagogia. [Dialogismo]. São Paulo: Hucitec, 2019.

Protocolos teatrais verbo-visuais: produção de sentidos para a prática teatral universitária. In: Bakhtiniana: Revista de Estudos do Discurso, v.8, p.106-123. São Paulo: PUCSP, 2013. DOI: https://doi.org/10.1590/S2176-45732013000200007.

GONÇALVES, J. C.; CASTILHO, T. Enunciado-Dançado: Approach Bakhtiniano Sobre O Ballet Clássico Na Escola. Revista Polêm!ca, v. 16, n.4, 2016. DOI: 10.12957/polemica.2016.26448.

GONÇALVES, M. B.; CASTILHO, T.; GABARDO JR., J. Corpos dançantes na escola: diálogos entre a educação performativa e a perspectiva bakhtiniana. Revista Bakhtiniana. Revista de Estudos do Discurso. v. 14, n. 3, 2019. DOl: https://doi.org/10.1590/2176-457337810

GREINER, C. O próximo corpo: uma possibilidade de discutir Laban em evolução. In: MOMMENSON, M; PRETRELA, P. (Orgs.). Reflexões sobre Laban, o Mestre do Movimento. São Paulo: Summus, 2006.

GRILLO, S. Esfera e Campo. In: BRAIT, B. Bakhtin: Outros Conceitos-Chave. São Paulo: Contexto, 2008.

LABAN, R. Dança Educativa Moderna. São Paulo: Ícone, 1990.

LABAN, R. Domínio do movimento. 5. ed. Edição organizada por Lisa Ullmann [tradu- ção: Anna Maria Barros De Vecchi e Maria Sílvia Mourão Netto]. São Paulo: Summus, 1978.

MARQUES, I. A. Ensino da Dança Hoje: textos e contextos. São Paulo: Cortez, 2011. 
Linguagem da dança: arte e ensino. São Paulo: Digitexto, 2010.

Imersão Caleidos. Janeiro de 2020. Notas de aula. São Paulo: Instituto Caleidos, 2020.

MCCAW, D. Bakhtin and Theatre: Dialogues with Stanislavsky, Meyerhold and Grotowski. Abingdon: Routledge, 2015.

Corpos em Bakhtin / Bakhtin's Bodies. Bakhtiniana, São Paulo, 14 (3): 35-56, julho/set. 2019. DOI: https://doi.org/10.1590/2176-457341642.

The Laban Sourcebook. Oxon: Routledge, 2011.

MEDVIÉDEV, P. 0 método formal nos estudos literários: introdução crítica a uma poética sociológica. Trad. Sheila Grillo e Ekaterina Vólkova Américo. São Paulo: Contexto, 2012.

MOMMENSON, M; PRETRELA, P (Orgs.). Reflexões sobre Laban, o Mestre do Movimento. São Paulo: Summus, 2006.

RENGEL, L. Fundamentos para análise do movimento expressivo. In: MOMMENSOHN, M.; PETRELLA, P. (Orgs). Reflexões sobre Laban, o mestre do movimento. São Paulo: Summus, 2006.

SCIALOM, M. LABAN PLURAL: Arte do Movimento, Pesquisa e Genealogia da práxis de Rudolf Laban no Brasil. São Paulo: Summus, 2017.

SILVA, E. R. Graduação em Dança no Brasil: professor como orientador e aluno como protagonista. In: ROCHA, T. (Org.). Graduações em dança no Brasil: o que será que será?. Joinville: Nova Letra, 2016

VOLÓCHINOV, V. Marxismo e filosofia da linguagem: problemas fundamentais do método sociológico na ciência da linguagem. Tradução, notas e glossário de Sheila Grillo e Ekaterina Vólkova Américo. São Paulo: Editora 34, 2017.

1 Trabalho realizado com o apoio da CAPES - Bolsa do Programa Nacional de Pósdoutorado e Bolsa de Doutorado.

2 Trata-se de um grupo de intelectuais russos, sendo eles artistas, linguistas, teóricos de diversos campos do conhecimento, que se reuniu regularmente por volta de 1919 a 1929, trazendo ao mundo uma noção sócio-semiótico-filosófica de construção de sujeitos, cultura e conhecimentos. Dentre os trabalhos mais expressivos, estão o de Mikhail M. Bakhtin, Valentin N. Voloshinov e Pavel N. Medviédev.

3 Os Protocolos Teatrais Verbo-Visuais, conforme defende Gonçalves (2013), reverberam como uma metodologia de trabalho nas Artes da Cena; uma abordagem dialógica para lecionar-avaliar-pesquisar, na qual se solicita aos alunos criarem formas poéticas de materializar suas sensações e entendimentos sobre as aulas, que hibridizem elementos das dimensões verbais e visuais.

4 It is impossible to prove that Bakhtin was aware of these cultural currents, but certainly there is a connection with his notion of the body and celebrative performance and those of appia, Laban and others - a connection with deserves a future research. 